\title{
Faktor Penentu Keputusan Konsumen dalam Mengkonsumsi Teh Celup Sariwangi (Studi Kasus pada Konsumen Tiara Dewata Group di Kota Denpasar)
}

\author{
EVA YUNITA, I MADE SUDARMA, \\ IDA AYU LISTIA DEWI
}

\author{
Program Studi Agribisnis, Fakultas Pertanian, Universitas Udayana \\ Jl. PB. Sudirman 80232 \\ Email: evayunitara@gmail.com \\ sudarmaimade@yahoo.com
}

\begin{abstract}
Determinants of Consumer Decisions in Consuming Sariwangi Dye Tea (Case Study on Tiara Dewata Consumer Group in Denpasar City)
\end{abstract}

The consumers' decision in purchasing Sariwangi tea bag products is affected by consumer characteristics and marketing mix elements. These variables affect the buying decision processes so as to produce a buying decision. This research was conducted at supermarkets in Denpasar City with the aim to identify the factors that play a role in consumer decision to buy Sariwangi tea bags and analyze decision processes of purchasing Sariwangi tea bags by consumers in Denpasar City. In this research, the method used was descriptive-quantitative analysis method and qualitative-descriptive analysis. The results showed that all variables had a role to the consumer's decision to consume Sariwangi tea, the variable that had the greatest role to the secondary factor was the social variable with the communality value of $17.29 \%$, while the individual variable with the communality value of $10.49 \%$ had the lowest role to the consumer's decision to consume Sariwangi tea bags. Considering that the seven variables truly have a role to consumer decisions consuming Sariwangi tea, then the producer should still pay attention to matters relating to these variables, especially social factors that have the most decisive role.

Keywords: Sariwangi tea, consumer decisions, factor analysis

\section{Pendahuluan}

\subsection{Latar Belakang}

Indonesia sebagai negara agraris kaya akan sumber daya alam yang salah satunya adalah bidang perkebunan, hasil perkebunan di Indonesia yang cukup terkenal adalah tanaman teh. Menurut Spillane (1992), tanaman teh (Camellia sinensis) familia dari Theaceae, diperkirakan berasal dari pegunungan Himalaya dan daerah-daerah pegunungan yang berbatasan dengan Republik Rakyat Cina, India, 
dan Birma. Dilihat dari pengolahan daun teh di Indonesia ada tiga jenis teh yaitu teh hitam, teh hijau, dan teh wangi.

Seiring dengan perkembangan zaman industri teh menghasilkan berbagai macam produk teh seperti teh kering, teh celup, dan teh dalam kemasan siap minum. Data dalam majalah marketing Top Brand (2013) berdasarkan pangsa merek teh, teh celup yang berhasil memimpin pa rtinggi dengan jumlah persentase $81 \%$ adalah

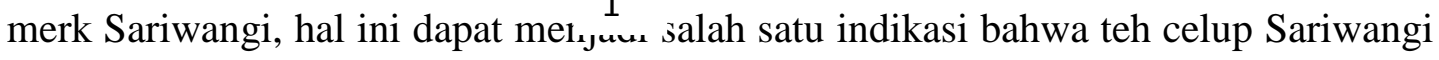
memiliki kekuatan pasar yang sulit untuk disaingi. Seiring semakin cerdasnya konsumen dan semakin bertambahnya pilihan produk yang tersedia di pasar, menimbulkan persaingan yang semakin ketat pada sisi produsen. Para produsen berusaha memperebutkan perhatian konsumen yang ada di pasar untuk membeli produknya.

Produsen teh Sariwangi terus berupaya mengantisipasi persaingan dengan menerapkan strategi pemasaran, agar dapat mempertahankan posisi pasar dan pelanggannya. Terdapat banyak faktor yang berpengaruh terhadap keputusan konsumen dalam pembelian suatu produk, selain dipengaruhi oleh karakteristik konsumen, dapat juga dipengaruhi oleh elemen-elemen bauran pemasaran (produk, harga, tempat dan promosi). Variabel-variabel tersebut saling mempengaruhi proses keputusan pembelian sehingga menghasilkan keputusan pembelian yang didasarkan pada pilihan produk, pilihan merek, pilihan penyalur, waktu pembelian, dan jumlah pembelian (Kotler, 2000).

Berdasarkan latar belakang masalah di atas maka dilakukan penelitian tentang "Faktor Penentu Keputusan Konsumen dalam Mengkonsumsi Teh Celup Sariwangi (Studi Kasus pada Konsumen Tiara Dewata Group di Kota Denpasar)". Hasil penelitian ini diharapkan dapat memberikan informasi kepada produsen teh celup Sariwangi dalam merancang strategi produknya untuk memperkuat posisinya dalam persaingan teh celup.

\subsection{Tujuan penelitian}

Berdasarkan permasalahan di atas, adapun tujuan yang ingin dicapai dalam penelitian ini sebagai berikut.

1. Mengidentifikasi faktor-faktor yang berperan dalam keputusan konsumen untuk membeli teh celup Sariwangi di Kota Denpasar.

2. Menganalisis proses keputusan pembelian teh celup Sariwangi oleh konsumen di Kota Denpasar.

\section{Metode Penelitian}

\subsection{Lokasi dan Waktu Penelitian}

Penelitian ini dilakukan di Kota Denpasar dengan mengambil Supermarket yang tergabung dalam Tiara Group, sebagai lokasi penelitian. Tiara Group terdiri dari Tiara Dewata, Tiara Gatsu, dan Tiara Monang-Maning. Penelitian ini dilakukan dari bulan Oktober hingga bulan Desember 2015. Pemilihan lokasi penelitian 
dilakukan dengan metode purposive sampling, adalah suatu cara penentuan lokasi penelitian secara sengaja (Sugiyono, 2003), dengan pertimbangan lokasi ketiga Tiara Group mewakili titik-titik wilayah Kota Denpasar. Ketiga lokasi tersebut umumnya menjadi pilihan masyarakat dalam berbelanja kebutuhan konsumsi rumah tangga termasuk teh.

\subsection{Data dan Metode Pengumpulan Data}

Jenis data yang digunakan adalah data kuantitatif dan data kualitatif. Data kuantitatif yaitu data yang berupa angka-angka atau informasi yang dapat diangkakan yaitu informasi tentang karakteristik responden, seperti usia, pendidikan terakhir dan frekuensi mengkonsumsi produk. Data kualitatif yaitu data yang tidak dapat dihitung yang berhubungan dengan masalah yang diteliti seperti gambaran produk, dan data hasil pengisian kuisioner tentang hasil penilaian pelanggan terhadap variabel-variabel pada teh celup Sariwangi seperti produk (X1), harga (X2), promosi (X3), distribusi (X4), budaya (X5), individu (X6), sosial (X7) oleh responden dengan skala ordinal.

Sumber data yang digunakan adalah data primer dan data sekunder. Data primer diperoleh langsung dari lokasi penelitian (Umar, 2003) melalui wawancara pada resonden di lokasi penelitian dengan menggunakan daftar pertanyaan yang meliputi informasi tentang karakteristik responden, data tentang hasil penilaian pelanggan terhadap variabel-variabel pada teh celup Sariwangi seperti produk (X1), harga (X2), promosi (X3), distribusi (X4), budaya (X5), individu (X6), sosial (X7). Data sekunder diperoleh dari instansi-instansi yang terkait dengan penelitian ini seperti Badan Pusat Statistik (BPS), data yang dgunakan meliputi luas wilayah Kota Denpasar, keadaan penduduk Kota Denpasar menurut umur, jumlah tenaga kerja Kota Denpasar, dan tingkat pendapatan penduduk Kota Denpasar.

Metode pengumpulan data yang digunakan adalah wawancara dan dokumentasi. Wawancara menggunakan kuisioner yang ditujukan kepada konsumen yang dijumpai di lokasi penelitian berisi pertanyaaan yang berhubungan dengan penelitian ini, sedangkan dokumentasi dengan mengambil foto pada saat melakukan wawancara dengan konsumen yang dijumpai di lokasi penelitian.

\subsection{Penentuan Populasi dan Sampel}

Populasi dalam penelitian ini adalah semua konsumen yang membeli dan mengkonsumsi teh celup Sariwangi di Kota Denpasar, karena yang membeli di Supermarket Tiara Dewata Group jumlahnya tidak diketahui, maka tidak dapat ditentukan kerangka sampel. Jumlah sampel ditentukan secara quota sampling, yaitu dilakukan sebanyak 60 responden dengan pertimbangan kebutuhan alat analisis SEM (PLS) dapat dilakukan dengan minimal sampel sebanyak 30 orang (Arikunto, 2006).

Pengambilan sampel responden dilakukan dengan metode purposive sampling yang merupakan teknik penentuan sampel dengan pertimbangan tertentu (Martono, 2010) yaitu konsumen yang mengambil keputusan pembelian teh celup yang ditemui 
di lokasi penelitian yang sedang membeli teh celup Sariwangi. Karakteristik responden yang dipilih adalah konsumen yang membeli dan mengkonsumsi teh celup Sariwangi minimal lima kali selama satu bulan.

\subsection{Metode Analisis Data}

Metode analisis dalam penelitian ini adalah metode analisis deskriptif kuantitatif dan analisis deskriptif kualitatif. Analisis yang digunakan dalam mengidentifikasi faktor-faktor yang berperan dalam keputusan konsumen untuk membeli teh celup Sariwangi menggunakan analisis Structural Equation Model (SEM) berbasis varians dengan pendekatan Partial Least Square (PLS). Dalam penelitian ini, analisis data pada SEM-PLS akan menggunakan bantuan software SmartPLS 2.0 M3. Langkah-langkah analisis model fit persamaan struktural dengan SEM-Partial Least Square adalah sebagai berikut (Haenlein, 2004).

1. Mendapatkan model berbasis konsep dan teori untuk merancang model struktural (hubungan antar variabel laten) dan model pengukurannya, yaitu hubungan antara indikator-indikator dengan variabel latennya.

2. Membuat diagram jalur (diagram path) yang menjelaskan pola hubungan antara variabel laten dengan indikatornya.

3. Konversi diagram jalur kedalam persamaan.

4. Melakukan evaluasi goodness of fit yaitu dengan evaluasi model pengukuran (outer model) dengan melihat validitas dan reabilitas. Jika model pengukuran valid dan reliabel maka dapat dilakukan tahap selanjutnya yaitu evaluasi model struktural. Jika tidak, maka harus kembali mengkonstruksi diagram jalur.

5. Intepretasi model.

Analisis deskriptif kualitatif merupakan penelitian yang berdasarkan pada pengumpulan data primer maupun data sekunder berdasarkan dokumentasi atau penelitian. Analisis deskriptif dalam penelitian ini digunakan untuk mengetahui proses pengambilan keputusan konsumen teh celup Sariwangi di Kota Denpasar yang meliputi tahap-tahap pengambilan keputusan pembelian yaitu pengenalan masalah, pencarian informasi, penilaian alternatif informasi, keputusan pembelian, dan perilaku setelah membeli. Data mengenai tahap-tahap pengambilan keputusan pembelian teh celup Sariwangi di Kota Denpasar diperoleh melalui beberapa pertanyaan pada kuisoner dan kemudian data dianalisis secara manual dengan cara memilih jawaban berdasarkan pilihan terbanyak pada jawaban kuisoner, sehingga dapat disimpulkan proses pengambilan keputusan konsumen teh celup Sariwangi di Kota Denpasar.

\section{Hasil dan Pembahasan}

\subsection{Faktor-faktor Yang Berperan dalam Keputusan Konsumen Membeli dan Mengkonsumsi Teh Celup Sariwangi di Kota Denpasar}

Langkah awal dalam permodelan PLS adalah spesifikasi model pada penelitian yang akan dilakukan. Spesifikasi model terdapat dua macam yakni merancang inner 
model dan outer model. Inner model adalah model structural yang menghubungkan antar variabel laten pada subtantive theory, yakni variabel $\mathrm{X}$ (eksogen) terhadap variabel Y (endogen). Variabel eksogen (X) dalam penelitian ini terdiri dari : produk (X1), harga (X2), promosi (X3), distribusi (X4), budaya (X5), individu (X6), dan sosial (X7). Variabel endogen (Y) dalam penelitian ini adalah keputusan konsumen. Diagram jalur hasil pengolahan data dengan bantuan software Smart-PLS (Partial Least Square) dapat dilihat pada gambar 1 dibawah ini.

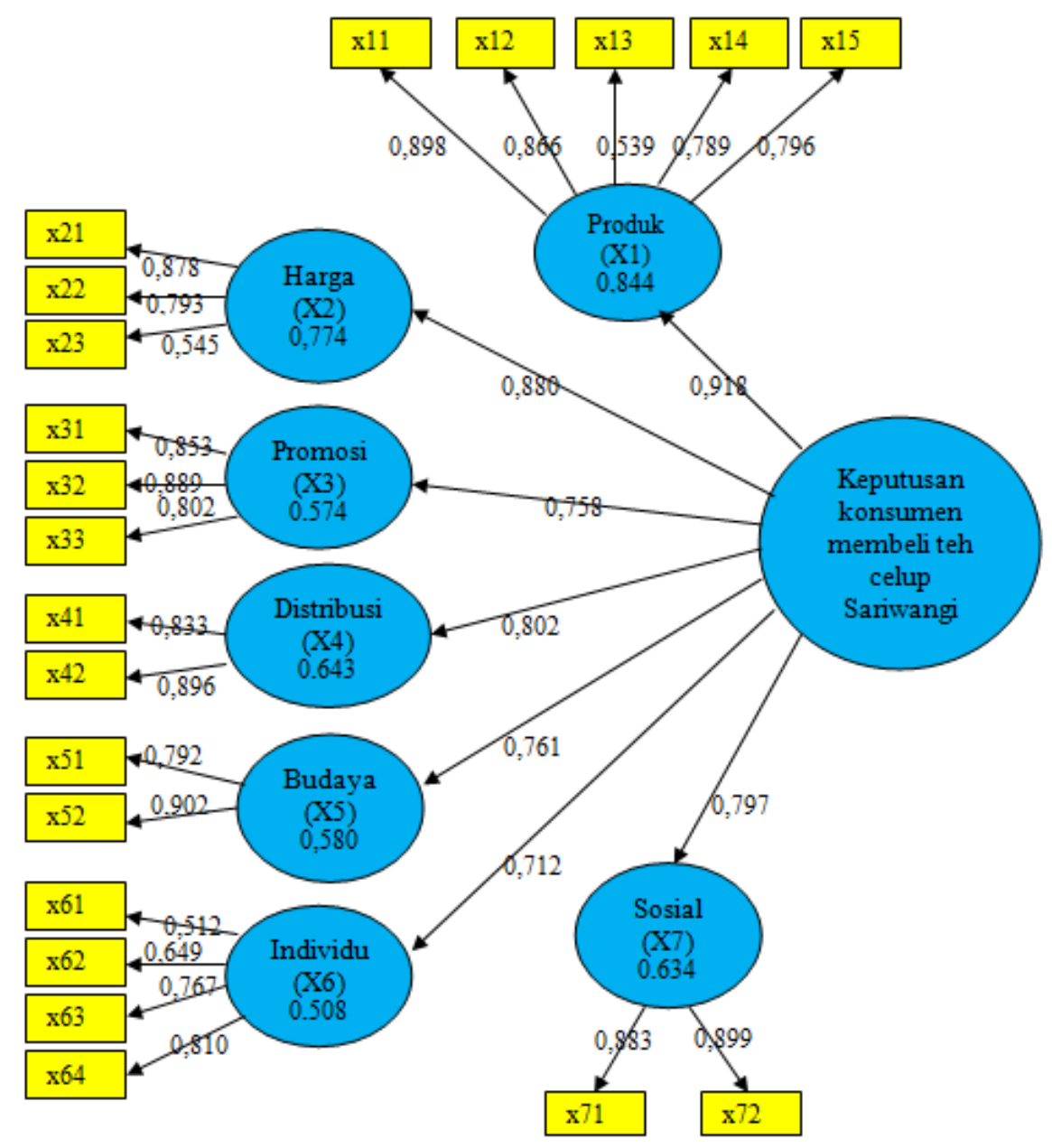

Gambar 1.

Spesifikasi Model Penelitian dengan Permodelan PLS

Hasil analisis permodelan PLS terhadap keputusan konsumen pada penelitian ini semua indikator yang terdiri dari : x11, x12, x13, x14, x15, x21, x22, x23, x31, $x 32, x 33, x 41, x 42, x 51, x 52, x 61, x 62, x 63, x 64, x 71, x 72$ dapat dikatakan valid untuk mengukur konstruk, atau memenuhi rule of thumb dari convergent validity, sebab semua indikator memiliki nilai loading factor diatas 0.5.

Menilai model struktural PLS dapat dilihat dari nilai R-Square untuk setiap variabel laten endogen sebagai kekuatan prediksi dari model struktural. Perubahan 
nilai R-Square digunakan untuk menjelaskan pengaruh variabel laten eksogen tertentu terhadap variabel laten endogen, apakah mempunyai pengaruh substantive. Nilai R-Square 0,67; 0,33; dan 0,19 untuk variabel laten endogen dalam model struktural menunjukkan model kuat, moderat, dan lemah (Chin, 1998 dalam Ghozali, 2011). Hasil dari PLS R-Square mempresentasikan jumlah varian dari konstruk yang dijelaskan oleh model.

Model struktural dapat dievaluasi dengan melihat nilai R-Square pada variabel endogen dan koefisien parameter jalur (path coeficient parameter) serta uji-t setiap hubungan seperti pada Tabel 1 dibawah ini.

Tabel 1.

Hasil Uji Model Struktural

\begin{tabular}{llll}
\hline Hubungan kausalitas & Nilai R-square $\left(\mathrm{R}^{2}\right)$ & $\begin{array}{l}\text { Koefisien } \\
\text { parameter }\end{array}$ & t-statistik \\
\hline Produk -> keputusan konsumen & 0.843624 & 0,918 & 61,365 \\
Harga -> keputusan konsumen & 0.773825 & 0,880 & 43,491 \\
Promosi -> keputusan konsumen & 0.574456 & 0,758 & 18,567 \\
Distribusi -> keputusan konsumen & 0.643036 & 0,802 & 21,959 \\
Budaya -> keputusan konsumen & 0.579813 & 0,761 & 17,160 \\
Individu -> keputusan konsumen & 0.507572 & 0,712 & 15,747 \\
Sosial -> keputusan konsumen & 0.634497 & 0,797 & 20,657 \\
\hline
\end{tabular}

Peranan variabel laten eksogen (produk, harga, promosi, distribusi, budaya, individu, sosial) terhadap variabel laten endogen (keputusan konsumen) pada tabel di atas dapat dijelaskan bahwa nilai R-square terbesar adalah variabel produk yaitu 0,843624 artinya nilai tersebut mengindikasikan bahwa keputusan konsumen mampu dijelaskan oleh variabel produk sebesar 84,4\%, dengan koefisien parameter sebesar 0,918 dan nilai T-statistik 61,365 pada taraf signifikan $(\alpha)=0,1 \quad(10 \%)$ yang menyatakan bahwa variabel produk benar memiliki peranan terhadap keputusan konsumen membeli teh celup Sariwangi, dan nilai R-square yang terendah adalah variabel individu yaitu 0,508 artinya nilai tersebut mengindikasikan bahwa keputusan konsumen mampu dijelaskan oleh variabel individu sebesar 50,8\%, dengan koefisien parameter sebesar 0,712 dan nilai T-statistik 15,747 pada taraf signifikan $(\alpha)=0,1(10 \%)$ yang menyatakan bahwa variabel individu benar memiliki peranan terhadap keputusan konsumen membeli teh celup Sariwangi.

Peranan dari ketujuh faktor primer dapat dilihat dari nilai communalities yang terbentuk. Faktor primer pada penelitian ini adalah produk (X1), harga (X2), promosi (X3), distribusi (X4), budaya (X5), individu (X6), dan sosial (X7). Semakin besar nilai communalities maka semakin besar pula peranan suatu variabel terhadap keputusan konsumen mengkonsumsi teh celup Sariwangi. 
Tabel 2.

Peranan Masing-masing Variabel terhadap Keputusan Konsumen Mengkonsumsi Teh Celup Sariwangi

\begin{tabular}{lcc}
\hline Variabel & Communalities (\%) & Peranan (\%) \\
\hline Sosial (X7) & 0,79 & 17,29 \\
Distribusi (X4) & 0,75 & 16,30 \\
Budaya (X5) & 0,72 & 15,69 \\
Promosi (X3) & 0,72 & 15,69 \\
Produk (X1) & 0,62 & 13,51 \\
Harga (X2) & 0,51 & 11,02 \\
Individu (X6) & 0,48 & 10,49 \\
\hline Jumlah & 4,59 & 100 \\
\hline
\end{tabular}

Variabel yang memiliki peranan terbesar terhadap keputusan konsumen mengkonsumsi teh celup Sariwangi adalah variabel sosial (X7) dengan nilai peranan sebesar $17,29 \%$ dan dengan nilai communalities sebesar 0,79\%. Hal ini menandakan bahwa faktor sosial seperti keluarga sebagai refrensi dalam membeli teh celup Sariwangi, dan rekan sekerja sebagai refrensi dalam membeli teh celup Sariwangi berperan penting dalam keputusan konsumen mengkonsumsi teh celup Sariwangi. Variabel individu (X6) memiliki peranan terendah terhadap keputusan konsumen mengkonsumsi teh celup Sariwangi yaitu hanya sebesar $10,49 \%$ dan dengan nilai communalities sebesar $0,48 \%$. Hal ini menunjukkan bahwa kepribadian seseorang seperti gaya hidup konsumen kurang berperan dalam keputusan konsumen mengkonsumsi teh celup Sariwangi.

\subsection{Proses Pengambilan Keputusan Konsumen Teh Celup Sariwangi di Kota Denpasar}

Menurut Kotler (1997) terdapat lima tahap dalam pengambilan keputusan pembelian yaitu pengenalan kebutuhan, pencarian informasi, evaluasi alternatif, keputusan pembelian,evaluasi setelah membeli. Hasil proses pengambilan keputusan konsumen teh celup Sariwangi dalam penelitian ini sebagai berikut.

1. Pengenalan kebutuhan

Proses pembelian oleh konsumen diawali sejak responden mengenali kebutuhan atau masalah. Kebutuhan tersebut dapat ditimbulkan oleh rangsangan internal atau eksternal. Tahapan pengenalan kebutuhan berdasarkan hasil kuisioner adalah responden merasa penting mengkonsumsi teh sehari-hari dalam keadaan santai di pagi hari, namun apabila tidak mengkonsumsi teh responden merasa biasa saja, dan responden dirumah biasanya mengkonsumsi jenis teh celup dibandingkan teh lainnya.

2. Pencarian informasi

Proses Pencarian informasi terjadi setelah konsumen terangsang kebutuhannya, responden berusaha untuk mencari informasi terhadap suatu produk yang mereka inginkan. Tahapan pencarian informasi, konsumen melakukan pencarian informasi 
tentang produk teh celup Sariwangi yang sebelumnya telah mereka ketahui mereknya, responden mendapatkan informasi mengenai produk Sariwangi pertama kali dari keluarga, selain itu responden mendapatkan informasi produk yang cukup jelas mengenai kelebihan produk melalui iklan teh celup Sariwangi di televisi, dalam pencarian informasi tersebut responden tidak membutuhkan waktu yang lama yaitu hanya satu hari atau dengan cepat.

3. Evaluasi alternatif

Kriteria evaluasi adalah atribut atau karakteristik dari produk dan jasa yang digunakan untuk mengevaluasi dan menilai alternatif pilihan. kriteria evaluasi pada produk teh celup Sariwangi mengacu pada pertanyaan kuisoner yaitu merek, harga, dan kemasan. Tahap evaluasi alternative ini adalah konsumen sudah yakin dengan produk teh celup Sariwangi karena konsumen sudah melewati tahap kebutuhan dan pencarian informasi. Alasan awal yang membuat responden tertarik adalah mereknya yang lebih terkenal sehingga membuat konsumen percaya dengan produk teh celup Sariwangi, Selain itu hal yang menjadi pertimbangan responden dalam membeli yaitu harga, harga beli teh celup Sariwangi dianggap masih dapat terjangkau untuk dibeli konsumen. Keluarga merupakan pihak yang paling berpengaruh dalam keputusan pembelian teh. Kondisi ini disebaban karena keluarga merupakan kelompok orang terdekat yang mudah dan cepat mempengaruhi perubahan perilaku responden, dalam hal ini perilaku dalam mengkonsumsi teh celup Sariwangi.

4. Keputusan pembelian

Proses selanjutnya setelah konsumen melalui tahap penilaian alternatif informasi, yaitu keputusan pembelian terhadap produk yang dibutuhkan dan diinginkan sebelumnya. Tahapan keputusan pembelian, responden telah menentukan untuk memutuskan pembelian teh celup Sariwangi. Proses pembelian responden dalam melakukan pembelian produk tersebut di supermarket dan warung terdekat. Teh celup Sariwangi yang biasanya dipilih adalah Sariwangi box isi 25pcs, jika pada tempat tersebut tidak terdapat produk yang diingkinkan maka mereka akan membeli produk teh celup merek lain.

5. Evaluasi setelah pembelian

Tahap evaluasi setelah pembelian ini konsumen akan melakukan proses evaluasi terhadap konsumsi yang telah dilakukannya. Hasil dari proses evaluasi pasca konsumsi adalah konsumen puas atau tidak puas terhadap produk teh celup yang telah dikonsumsinya. Tahap perilaku pasca pembelian berdasarkan hasil kuisioner, $88 \%$ responden merasa puas terhadap produk teh celup Sariwangi, sedangkan $12 \%$ responden merasa tidak puas karena tidak cocok dengan selera mereka yang menyebabkan responden tersebut akan membeli teh celup dengan merek lain. Apabila teh celup Sariwangi mengalami kenaikan terhadap harga produknya $47 \%$ responden mengatakan akan tetap membeli teh celup Sariwangi dan $43 \%$ responden mengatakan tidak akan membelinya, serta $10 \%$ responden mengatakan tergantung akan membelinya atau tidak, sehingga dapat dikatakan hampir sebagian responden akan tetap setia mengkonsumsi teh celup Sariwangi. 


\section{Simpulan dan Saran}

\subsection{Simpulan}

Berdasarkan hasil penelitian dapat disimpulkan bahwa faktor-faktor yang berperan dalam keputusan konsumen membeli dan mengkonsumsi teh celup Sariwangi adalah produk, harga, promosi, distribusi, budaya, individu, sosial. Variabel yang memiliki peranan terbesar terhadap faktor sekunder adalah variabel Sosial (X7) dengan nilai comunalities sebesar 17,29\%, sedangkan variabel individu (X6) dengan nilai comunalities sebesar 10,49\% memiliki peranan terendah terhadap keputusan konsumen mengkonsumsi teh celup Sariwangi. Proses keputusan konsumen teh celup Sariwangi di Kota Denpasar melalui beberapa tahapan yaitu pengenalan kebutuhan, pencarian infomasi, evaluasi alternative, keputusan pembelian, evaluasi setelah pembelian. Responden yang menjadi konsumen aktif produk teh celup Sariwangi $88 \%$ merasa puas, sedangkan sisanya $12 \%$ responden tidak merasa puas sehingga responden tersebut beralih mengkonsumi teh celup merek lain.

\subsection{Saran}

Berdasarkan hasil penelitian dapat disarankan agar produsen memperhatikan ketujuh variabel, khususnya variabel sosial karena memiliki peranan penentu paling besar. Melihat variabel yang berhubungan dengan strategi pemasaran yang dilakukan oleh perusahaan memiliki peranan tidak terlalu besar, maka manajemen perusahaan sebaiknya lebih meningkatkan kualitas strategi pemasaran agar variabel produk, harga, distribusi, dan promosi dapat menjadi faktor penentu utama konsumen dalam mengkonsumsi teh celup Sariwangi, sehingga keputusan konsumen dapat dikendalikan oleh perusahaan.

\section{Ucapan Terima Kasih}

Ucapan terima kasih ini peneliti tujukan kepada seluruh pihak yang telah membantu dalam pelaksanaan penelitian hingga karya ilmiah ini bisa dipublikasikan dalam bentuk E-jurnal.

\section{Daftar Pustaka}

Arikunto, S. 2006. Prosedur Penelitian Suatu Pendekatan Praktik. Jakarta. Penerbit: Rineka Cipta.

Ghozali, I. 2011. Structural Equation Modeling, Metode Alternatif dengan Partial Least Square. Semarang. Penerbit: Universitas Diponegoro.

Haenlein, M. 2004. A Beginner's Guide to Partial Least Square Analysis. Journal Statistic.Vol. 03.Page. 290-291

Kotler, P. 1997. Manajemen Pemasaran. Jakarta. Penerbit: PT. Prenhallindo.

Kotler, P. 2000. Manajemen Pemasaran (terjemahan). Edisi millenium. Jakarta Penerbit: PT. Prenhallindo.

Martono, N. 2010. Metode Penelitian Kuantitatif. Jakarta. Penerbit: PT Raja Grafindo Persada. 
Spillane, J.J. 1992. Komoditi Teh Peranannya Dalam Perekonomian Indonesia. Yogyakarta. Penerbit: Kanisius

Sugiyono.2003. Metode Penelitian Bisnis. Bandung. Pusat Bahasa Depdiknas.

Top Brand. 2013. Top Brand Index. http://www.topbrand-award.com/ (Diakses 25 Februari 2015).

Umar, H. 2003. Metode Riset Komunikasi. Jakarta. Penerbit: PT Gramedia Pustaka Utama. 